\title{
THE ROLE OF THE MEDIA IN TEACHING FRENCH AT NON-LANGUAGE FACILITIES DURING THE PANDEMIC PERIOD- DISTANCE LEARNING
}

\author{
Irina Meshkova ${ }^{1}$, Olga Sheremetieva ${ }^{2}$, Larissa Spynu ${ }^{3}$ \\ ${ }^{1}$ Assoc. Prof. PhD., Peoples' Friendship University of Russia (RUDN University), Russia, \\ meshiran1@gmail.com \\ ${ }^{2}$ Senior lecturer, Peoples‘ Friendship University of Russia (RUDN University), Russia, \\ oasher@mail.ru \\ ${ }^{3}$ Assoc. Prof. PhD., Peoples‘ Friendship University of Russia (RUDN University), Russia, \\ lorance@rambler.ru
}

\begin{abstract}
Language as a special type of social informational connections is both a way of expressing accumulated knowledge and a basis for the formation of the new ones. With the help of language, in the process of active cognitive activity, the informational picture of the world changes. Modern society is also constantly changing. The language follows these changes which are best reflected in mass media language. Mass media plays an important role, highlights the most relevant events, which became especially important during the pandemic. The mass media are viewed as a special socially-orientated information system that performs an important communicative function in the process of teaching a foreign language. With the help of media materials, an act of communication between people is carried out, based on mutual understanding, which involves the formation of communicative and social competencies.

The use of authentic media materials, such as the print press, audio and video sites, in the process of teaching a foreign language brings students as close as possible to the real information situation. For example, the use of authentic French media texts in foreign language classes, depending on the level of proficiency in the language of the learners, makes it possible to better understand and explain the sociopolitical and cultural factors in the life of French society. Mass media materials have a number of advantages in teaching a foreign language, contribute to the study of current and significant events in the countries of the target language, offering interesting and relevant country-specific material. The use of video and audio materials in the classroom helps to teach the perception and understanding of speech by ear, and visualization of the perception of information in the study of a foreign language acts as an effective auxiliary tool. The language of the media is considered as a special language associated with the described events, which is additional didactic material for completing written and oral assignments from retelling an article to holding debates on important issues of our time, forming intercultural associations. Various types of media texts contribute to the achievement of communicative competence, develop four language competencies such as comprehension and generation of written and spoken language, and form critical thinking. Using printed, audio and video texts in foreign language classes, the teacher must analyse the material and formulate pedagogical goals based on the topic, type of text and its lexical and grammatical content.
\end{abstract}

From a didactic point of view, the media makes it possible to use video teaching methods, developing media and information competence in trainees. For example, the French-language press implicitly conveys certain cultural features, gives a real idea of society, thereby helping the study of French as a foreign language. During classes with students, we work with media texts sequentially (step by step), offering exercises and tasks for understanding, assimilation and further use in practice of the studied features of the use of lexical and grammatical structures in the language of the press, information data, starting from the definition of the 
main topic of the document to the creation of an oral or written statement on the topic under study, using a step-by-step method. Students should learn how to perform tasks such as answering open and closed questions, choosing one of the proposed answer options (multiple choice), tasks for recreating text, analysis and synthèse. In the classroom, we actively use online documents from newspapers and information sites Monde, Figaro, Euronws, RFISavoirs, TV5Monde, giving preference to the most relevant texts. For example, when working with documents from the TV5 Monde website, we invite students to do the exercises from this website in a group and at home individually.

Thus, the use of various media materials, thanks to computer communication technologies, makes it possible to make it more modern, to improve the process of teaching foreign languages, to implement in a new way methods that activate the creative activity of students, develops the ability to participate in virtual discussions on various educational sites and thematic forums, helps carry out joint creative projects..

Keywords: Media texts, teaching a foreign language, French-language press, a communicative function,the process of active cognitive activity.

\section{INTRODUCTION}

Information communications play a vital role in all areas of human activity. The information resources of society are currently becoming a determining factor in its development, both in scientific, technical and social terms. The problem of the impact of language on a person, his way of thinking and his behavior, is directly related to the means of mass communication.

The transmission of information can occur only if this information interests you or if it is assumed that it can influence the behaviour of people. Linguistic communication plays the most important role in Human communication. Communication is understood as an act of interaction, like a link of interaction between two or more individuals, based on mutual understanding, as well as the transfer of information from one person to another or a number of persons (Robert, Rosen, Reinhardt, 2011).

Communication forms mass consciousness on the basis of stereotypes that express the habitual, stable ideas of people about any phenomenon, formed under the influence of specific social conditions and previous experience. The mass media (newspapers, magazines, radio, television, Internet resources) play an important role in the formation of mass consciousness.

The mass media can be considered as a special social information system that performs the functions of communication, affects the mass consciousness and represents the current regional geographic material. The use of the media in teaching foreign languages is constantly increasing, which was especially evident during the Covid-19 pandemic, when classes were mainly conducted in a remote format. The Internet makes it possible to enter the global information space, provides access to information sources in any part of our planet. Recently, many newspapers and magazines, including French ones, have their own websites. The development of the Internet has greatly influenced the study of foreign languages, making it faster and easier to work with authentic sources.

Information technology provides an opportunity to use various media to improve the learning process, which, of course, increases interest in the subject being studied. The media bring students as close as possible to real information sources and "immerse" them in the world of current events. Electronic means of communication, the Internet, can be considered "hybrid" because they combine written text, picture and sound, reflecting the relationship at a distance between the sender / author of the text and the recipient, the reader. The language of the press is special, special in terms of the use of linguistic means. These can be different types of texts, for example, information notes, articles of a different nature (economic, legal, political, etc.), using special thematic terminology. Since the press is addressed to audiences with different levels of culture, this is reflected in the choice of vocabulary (literary or spoken language), grammar and syntax.

\section{LITERATURE REVUE AND METHODOLOGY}

Some researchers believe that from a didactic point of view, the media contribute to the development of additional knowledge, developing the media competence of learners (Cuq, Gruca, 2017). The widespread use of media materials in foreign language lessons can be considered as an additional study to the existing 
textbooks and manuals, as a resource providing authentic modern material, giving additional motivation for learning and influencing the development of students' critical thinking, as well as the formation of their communicative, linguistic and intercultural competencies. For pedagogical purposes, there is a specific typology that includes purely informational articles, narratives, studies, opinions of foreign authors, comments.

Modern communication technologies make it possible to develop the creative activity of students, allowing them to participate in virtual discussions on various educational sites and thematic forums, to carry out joint creative projects together with students from various educational institutions in different cities and countries (Bagnoli, Dotti, Praderi, Ruel, 2010). The inherent properties of new technologies, such as their interactivity, polymodality, multimedia, content visualization, play an important role in teaching foreign languages. The media are an important mean of developing language communication competencies, helping to develop skills such as writing, reading, participating in a conversation, and the ability to express thoughts in oral and written forms. The media form language competencies in grammar, vocabulary, semantics, phonology, spelling (Porcher, 2004; Albert, 2008).

Communication is closely related to social competence, which does not exist outside a particular society, depends on the main characteristics of the life of a given society: economic and political life, historical and cultural norms, organization of social relations. Social competence is not only a certain socialization of a person, but also the ability to achieve success (Cuq, 2003).

The authors propose to use authentic media texts, starting from the A1 + A2 level, when there is a certain level of language proficiency, a sufficient lexical and grammatical reserve has been accumulated. Authentic periodicals are used as material for mastering social and political vocabulary. In parallel with getting a general idea of the French press, the student learns the specific vocabulary of the media, enriches his vocabulary with common vocabulary, which is found in various articles.

Authentic documents contain valuable linguistic and cultural information, create conditions for mastering communicative competence. The cultural component of media texts helps to develop intercultural competence among students, introducing them to the realities of life in different countries of the world (civilizational competence). Studying the language of another country, its mores and customs through media texts, the existing prejudices associated with another culture disappear. The cultural aspect is one of the important functions of the media in teaching a foreign language (Byram, 1992). Studying and understanding the culture of the countries of the target language, interest in finding a common language and in finding a compromise in difficult situations, helps to use the accumulated communication skills in the future.

The media also helps in shaping students' critical thinking. You can take a certain relevant topic, then study and discuss different points of view, consider how this topic is covered in various media (Aknazzay, Castincaud, 2009; Cipra, Hermelin, 1984). Based on the material of a significant number of texts, the stages of teaching abstracting are worked out, starting with paraphrasing expressions, individual phrases, then paragraphs, a short text, a relatively large newspaper text, completing this complex process by retelling several single-theme texts (synthèse). Thus, the acquisition of skills in abstracting in French takes place, Such work with media texts is relevant, since mastering such types of retelling - résumé, compte rendu, synthèse is required to obtain international DELF / DALF certificates.

When selecting media materials for classes, the teacher takes into account the level of knowledge of students, selects texts of a certain volume, topic, complexity. The texts should be interesting for students and arouse the desire to read and understand the text in a foreign language. The teacher, being a mediator in the educational process, helps students, for example, when watching a video, in understanding the material, having previously developed a lesson scenario based on didactic, pragmatic, motivational goals.

In recent years, in foreign language classes, as additional material, they increasingly use Internet resources. A combination of newspaper texts and video materials on the same topic gives good results. That is why, for greater motivation and diversity of the educational process when teaching a foreign language, both in class in the classroom and independently when doing homework, video and audio materials from the media are widely used, which contribute to the development and understanding of speech by ear and its reproduction.

Some media sites, for example, RFISavoirs (RFISavoirs), TV5MONDE (TV5MONDE), offer for pedagogical use a variety of materials for levels of French language A1 - B2, allowing you to work out general language skills and skills in core competencies. For example, the use of the Internet version of Figaro allows you to expand and enrich the existing lexical and grammatical knowledge, find information on the peculiarities of the use of vocabulary, grammar, history of persistent expressions. 
The assignments are completed in stages using a sequential method. So, working with audio-video materials assumes that after the first listening, the information should interest the student and he should understand what is at stake. The next stage of work involves the ability to reproduce the text, both orally and in writing in the classroom or independently (the stage of understanding and analysing the authentic text). This stage can be characterized as stimulating, arousing interest in the language of the media. Students learn to speak on a proposed topic in an appropriate speaking style (Colavecchio, Pâquier, Van Dixhoorn, 2021; Charaudeau, 2011).

To consolidate the material, the authors propose to perform various exercises and assignments, depending on the type of text, the level of the group, the nature of the media. For example, when working with a white paper, students should find answers to basic questions: Who? What? Where? When? Why?. When compiling the synthèse, students must provide comprehensive and comprehensive information about the event, and the print review assumes the ability to use a variety of quotes and comments. When working on a special documentary article in print or electronic form, it is necessary to be able to analyse various research results on the topic under study. Most of the teachers note the important role of the media in teaching competencies such as Speaking and Writing. Students develop creative thinking, linguistic competence, the ability to take part in debates, negotiations, make messages, reports and analytical reviews.

\section{RESULTS}

The formation of the skills and abilities of oral and practical speech provides for the sequential performance of various exercises and tasks. For example, studying the title and subtitle of texts / articles, answering questions, Multiple Choice, filling in the gaps, finding redundant information, determining the correct order of fragments of the source text, compressing the text, reformulating individual phrases and the whole text, finding additional information on the subject of the studied text, preparing oral communication, writing an essay, your own newspaper article, conducting round tables and role-playing games on the studied topic using the material learned. Working with video materials, for example, dubbing a fragment or the entire document, allows you to learn to understand speech by ear with visual support, improve the style and tempo of speech, and also analyze the correctness of the task when listening to self-recording. At the same time, during the work of students, the teacher listens to the audio recordings made by the students and corrects errors. This type of work saves time in the classroom for other tasks. This type of task has been widely used by the authors to motivate students to work remotely during the Covid-19 pandemic and have shown good results. Work with media materials, both the print press and media Internet sites, can be carried out both in individual and group formats. The proposed exercises for working with paper and electronic media materials have been shown to be effective during the Covid-19 pandemic.

The individual form presupposes the independent fulfilment of the set didactic tasks by the trainees, namely: the formation and consolidation of new skills and abilities, the generalization of the passed material. It is implemented most often in homework and test assignments. Group work is used when completing tasks for the joint search for information and the collective solution of the problem. Pair work, as one of the types of group work, is mainly used to perform various communicative language exercises. Thus, when studying a foreign language using a variety of media materials, the social competence of students is formed. As a result the ability to defend their point of view grows, at the same time taking into account the opinion of the interlocutor.

\section{CONCLUSIONS}

One of the functions of the media is social, which includes specific linguistic and cultural components, and also forms moral values. This is also an important educational function in teaching foreign languages. Working with media texts helps to increase the general educational level of students. Being a huge source of various authentic documents used as additional educational material, the media helps to develop not only language skills, but also the critical thinking skills of learners of foreign languages.

The communicative approach involves the use of authentic documents from the everyday life of the country of the studied world and the world. The media provide authentic written documents, authentic visual documents, and even authentic electronic written documents that enable the study of a modern foreign language.

The choice of materials depends on the level of proficiency in the language of the trainees and the educational tasks assigned to them. Media materials are used as an additional resource to existing textbooks on a common foreign language (eg French as a foreign language "Le français général"). The use of a variety of media materials allows you to diversify and enrich the educational process, make classes 
more attractive for students, increase their motivation and socio-cultural level. Thus, the language of the media makes an undeniable contribution to the teaching of foreign languages.

\section{ACKNOWLEDGEMENT}

This paper has been supported by the RUDN University Strategic Academic Leadership Program.

\section{REFERENCE LIST}

Robert, J.-P., Rosen, E., Reinhardt, C. (2011). Faire classe en FLE : une approche actionnelle et pragmatique. Paris : Hachette.

Cuq, J.-P., Gruca, I. (2017). Cours de didactique du français langue étrangère et seconde. PUG.

Bagnoli, P., Dotti, E., Praderi, R., et Ruel, V. (2010). La perspective actionnelle : Didactique et pédagogie par l'action en Interlangue. https://www.myenglishpages.fr/docs_a_telecharger/dida/perspective_actionnelle_bagnoli.pdf

Porcher, L. (2004). Enseignementdes langues étrangères. Paris: Hachette Education.

Albert, P. (2008). La presse française. Paris, Éd. La Documentation française, coll. Études de la presse française.

Cuq, J.-P. (2003). Dictionnaire de didactique du français langue étrangère et seconde. Paris: CLE International.

Byram, M. (1992). Culture et éducation en langue étrangère. Paris :Hatier.

Aknazzay, A., Castincaud, F. (2009). Travailler sur la presse écrite à l'École. Collection des hors-série numériques : CRAP Cahiers pédagogiques.

Cipra, A., Hermelin, C. (1984). La presse : un outil pedagogique. Paris: Éditions Retz.

RFISavoirs,(https://savoirs.rfi.fr/ru/apprendre-enseigner/ 02.10.2021

TV5MONDE (https://langue-francaise.tv5monde.com/ 02.10.2021

Colavecchio, G., Pâquier, E., Van Dixhoorn, L. (2021). Les médias en classe: Kit pédagogique pour la classe de langue. PUG.

Charaudeau, P. (2011). Les médias et l'information: l'impossible transparence du discours. 2-e edition revue et augmentee. De Boeck-Ina, Bruxelles. 